\title{
Design and Implementation of the Evaluation System of the Post Practice in Higher Vocational Colleges Based on AHP
}

\author{
Wen Lin ${ }^{1, a}$ \\ ${ }^{1}$ Heilongjiang Institute of Architectural Technology, Academic Affairs Department, Heilongjiang, Harbin \\ 150025, China \\ al2004alj@163.com
}

Keywords: AHP; Higher Vocational Colleges; The Evaluation System of the Post Practice; Design; Implementation

\begin{abstract}
For the Higher Vocational Colleges, post practice is not only the key link of the training of talents, but also an important part of Higher Vocational Education plan. In order to have a more holistic understanding of the post practice, it must be realized by a specific evaluation system of internship. Nowadays, the evaluation system of post practice in Higher Vocational Colleges is relatively single and rigid in form and content, and the feedback is not in time. To solve this problem, it is a good choice to create an evaluation model through AHP. Based on AHP, the paper concludes three evaluation index systems and models covering performance on students' practice, teachers' guidance on practice and guidance from practice units. Furthermore, the weight of the three models are analyzed to provide more valuable feedback to Higher Vocational Colleges, which is beneficial for the schools to assess their teaching performance.
\end{abstract}

\section{Introduction}

Post practice refers to a practice activity that students are required to participate in after finishing basic courses, professional courses and professional practice after school. They will work at a specific post in a company with other workers while studying. The Education Ministry indicates in the 'On the trial work of the Vocational College, the combination of work and study, and a half work and half study' that colleges should actively recommend students to enterprises for post practice, form a model in which school as the main body works with enterprises jointly to educate and train students. From the above-mentioned, it is obvious that post practice is of great importance to Higher Vocational College. The construction of certain evaluation system is necessary for the holistic knowledge of the situation of student's post practice. Based on AHP, the paper concludes three evaluation index systems and models covering performance on students' practice, teachers' guidance on practice and guidance from practice units, and analyzes the process of the weight realization of the three models.

Post practice is the key link in the process of training of talents in higher vocational colleges, and an important carrier to promote the formation of students' professional knowledge, professional skills and professional attitude, and an effective way for the Higher Vocational Colleges to promote the reform of the personnel training mode combining practice and study.

AHP is an abbreviation for Analytic Hierarchy Process, a hierarchical and quantitative method for analyzing human thinking process, which is a quantitative and qualitative analysis method proposed by A.L.Saaty, American operational research expert, in 1970s, aiming at solving multi-objective and standard-complex problems in an effective and simple way. He makes various factors involved in the complex and systematic problems clear by dividing interrelated and orderly levels, and gives a quantitative description of the the relative importance between elements in the same level according to qualitative judgment, and determines the relative weight value of each level by using the mathematical method. Finally, according to the value of the various indicators and their weights, a comprehensive evaluation of the problem studied is made. The principle is to divide the whole index system (in three case). The bottom node is the concrete index of the effect, which is called "sub index layer" ; the second layer is "index class", which will organize a number of 
relevant indicators into a class (or subsystems) to reflect the performance of a larger category; the top layer is the target layer, which has only one node, which represents the results of the final evaluation. The whole index system, from the top to the bottom, is gradually reduced, and the index is gradually refined. In the actual operation, the use of a certain evaluation method can get the evaluation value of the top level indicators through calculating the underlying various refinement indicators —— the final evaluation result. Specific distribution is shown in Figure 1:

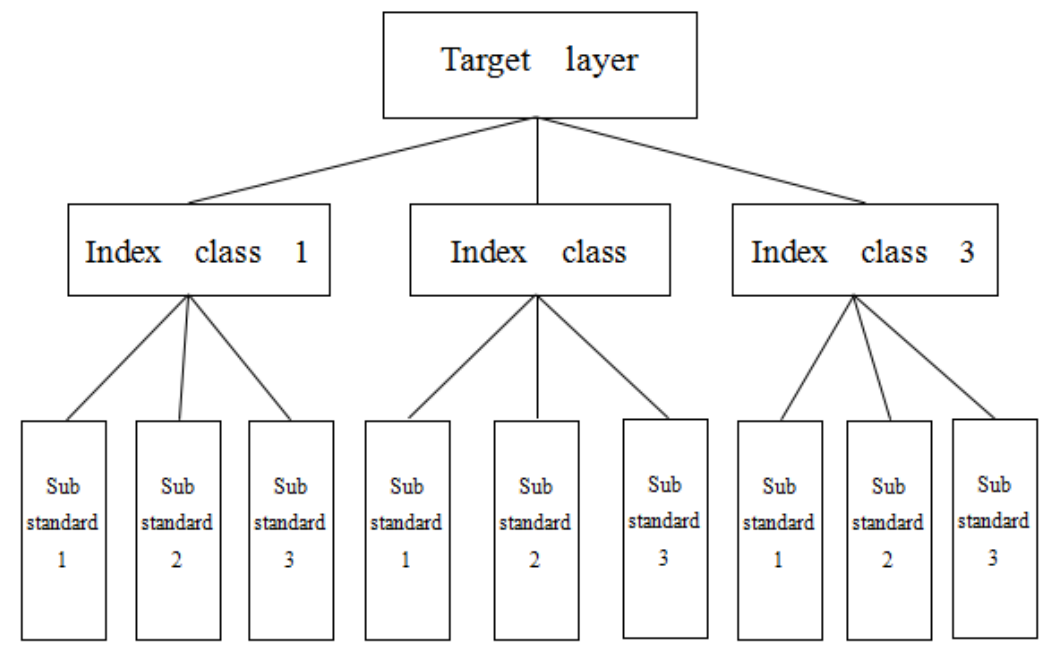

Fig. 1 of AHP distribution

The characteristic of AHP is that the input information is the choice and the judgment of the decision maker, in another word, the whole decision-making process is reflected by the decision maker's understanding of the problem. At the same time, it also has the characteristics of simplicity, systematicness and practicality. Its practicality lies in that AHP can carry on not only the quantitative analysis, but also the qualitative analysis. Generally speaking, there are three kinds of people's decision-making: causal judgment, probability inference and system inference. AHP more often analyzes problems as a system, belong to system inference.

\section{Construction of AHP mathematical model}

AHP is a new kind of mathematical method, which is used to carry out multi-level weight analysis. In the construction of AHP model, it can be divided into five steps.

(1) Construction of the hierarchy model. After analyzing the problems in depth, when the factors are divided into different levels (such as target layer, criterion layer, index layer, design layer, measure layer, and so on), the hierarchical structure and the subordinate relationship of the factors are illustrated by the block diagram. When there are many factors in a certain level, it can be further divided into several levels.

(2) Construction of the judgment matrix. The value of the elements of the judgment matrix reflects people's understanding of the relative importance of each factor, generally the scaling method of digital 1-9 and its reciprocal is applied. In order to compare the relative importance of the elements of $i$ and $j$ in the same level, the 1-9 scaling method can be used to compare the different evaluation indexes to construct judgment matrix. Saaty used a variety of comparative scales:1-3,1-5,1-6, ..1-11; $(d+0.1)-(d+0.9)$, like $d=2,3,4,5,6, \cdots ; 1 p-9 p, p=2,3,4,5, \cdots, 27$ comparative scales in total were used. Of course, through the research results, it shows that the 1-9 scale is not only simple, but effective as well. So 1-9 scale is more applied in the construction of judgment matrix. The specific meaning of the content is shown in Table 1. 
Table 1 AHP method to determine the meaning of matrix

\begin{tabular}{|l|l|}
\hline Scale value & the specific meaning of the content \\
\hline$B_{i j}=1$ & $\begin{array}{l}\text { element } \mathrm{i} \text { and element } \mathrm{j} \text { have the same importance to the } \\
\text { upper layer }\end{array}$ \\
\hline $\mathrm{B}_{\mathrm{ij}}=3$ & element $\mathrm{i}$ and element $\mathrm{j}$ are slightly important \\
\hline $\mathrm{B}_{\mathrm{ij}}=5$ & element $\mathrm{i}$ and element $\mathrm{j}$ are important \\
\hline $\mathrm{B}_{\mathrm{ij}}=7$ & element $\mathrm{i}$ and element $\mathrm{j}$ are strongly important \\
\hline $\mathrm{B}_{\mathrm{ij}}=9$ & element $\mathrm{i}$ and element $\mathrm{j}$ are extremely important \\
\hline $\mathrm{B}_{\mathrm{ij}}=2,4,6,8$ & $\begin{array}{l}\text { the importance of element } \mathrm{i} \text { and element } \mathrm{j} \text { is between } \\
\mathrm{B}_{\mathrm{i}}=2 \mathrm{n}-1 \text { and } \mathrm{B}_{\mathrm{ij}}=2 \mathrm{n}+1\end{array}$ \\
\hline $\mathrm{B}_{\mathrm{ij}}=1,1 / 2, \cdots, 1 / 9$ & $\begin{array}{l}\text { If the relative importance of the element } \mathrm{I} \text { and element } \mathrm{J} \text { is } \\
\text { compared by using the numerical index, the } \mathrm{J} \text { and } \mathrm{I} \text { are } \\
\text { compared with the reciprocal of the value, that is, Bij=1/Bij }\end{array}$ \\
\hline
\end{tabular}

According to the table, the AHP, which judges matrix scaling, schedules the order of the relative advantages and disadvantages of each index, construct, in order, the judgment matrix $\mathrm{B}$ of each evaluation index, such as:

$$
B=\left[\begin{array}{cccc}
b_{11} & b_{12} & \cdots & b_{1 n} \\
b_{21} & b_{22} & \cdots & b_{2 n} \\
\cdots & \cdots & \cdots & \cdots \\
b_{n 1} & b_{n 2} & \cdots & b_{n n}
\end{array}\right]=\left(b_{i j}\right) n \times n
$$

In which $b_{i j}=\frac{b_{1 i}}{b_{1 j}}, i, j=1,2,3, \cdots, n$

(3)Hierarchical single ranking and its consistency check. The vector $\mathrm{W}$ is obtained by determining the eigenvalues of matrix $\mathrm{B}\left(B_{W}=\lambda_{\max } W\right)$. After normalization, the corresponding factors of the same level is for the sort weights of the relative importance of a factor of the first level, which is known as Hierarchical single ranking. To make a consistency test for a single row of hierarchical single ranking (or judgment matrix), it is necessary to calculate the consistency index $C I=\frac{\lambda_{\max }-n}{n-1}$. For the judgment matrix, the values of the average random consistency index RI are shown in Table 2.

Table 2 average consistency index table

\begin{tabular}{|l|l|l|l|l|l|l|l|l|l|l|l|}
\hline $\mathrm{n}$ & 1 & 2 & 3 & 4 & 5 & 6 & 7 & 8 & 9 & 10 & 11 \\
\hline $\mathrm{RI}$ & 0.00 & 0.00 & 0.58 & 0.90 & 1.12 & 1.24 & 1.32 & 1.41 & 1.45 & 1.49 & 1.51 \\
\hline
\end{tabular}

When the random consistency ratio is $C R=\frac{C I}{R I}<0.10$, it is considered that the results of hierarchical single ranking have a satisfied consistency, otherwise, element value of the judgment matrix need to be adjusted.

(4) Overall hierarchical ranking. Overall hierarchical ranking is defined as calculating the relative importance of all factors of the same level to the high level (overall goal). This process is from the highest level to the lowest level layer by layer. If the upper level A contains $\mathrm{m}$ factors, like $A_{1}$ 、 $A_{2} 、 \cdots, A_{m}$, of which the order of the ranking weights is $a_{1}, a_{2}, \cdots, a_{m}$, the next level $B$ contains $n$ factors ,like $B_{1} 、 B_{2} 、 \cdots B_{n}$. Their hierarchical single ranking weights against factor $A_{j}$ is $b_{1 j}, b_{2 j}, \cdots$ 、 $b_{n j}$ (when $B_{K}$ is irrelevant to $\left.A_{j} b_{k j}=0\right)$. At this time, the overall ranking weights of level $B$ is $\sum_{j=1}^{m} a_{j} b_{1 j}, \sum_{j=1}^{m} a_{j} b_{2 j}, \cdots, \sum_{j=1}^{m} a_{j} b_{n j}$. 
(5)The consistency check of the overall hierarchical ranking. This step is also carried out from high to low layer by layer. If the consistency index of certain factors of level B against single ranking $A_{j}$ is $\mathrm{CI}$, and the corresponding average random consistency index is RIj, the random consistency ratio of level $\mathrm{B}$ is $C R=\frac{\sum_{j=1}^{m} a_{j} C I_{j}}{\sum_{j=1}^{m} a_{j} R I_{j}}$. Similarly, when $\mathrm{CR}<0.10$, it is considered that the total hierarchical ranking results are satisfactory, otherwise the element value of the judgment matrix should be readjusted.

\section{The application and implementation of AHP in the evaluation system of Higher Vocational Colleges post practice}

Only when the evaluation index system of the post practice in the Higher Vocational Colleges is scientific, can it, to the greatest extent, reflect if the teaching object of the post practice is met, and if the feedback is valuable for the school involved. So, its evaluation standard is different from other courses, including scientific evaluation through three aspects: students' performance on the post practice, teacher's guidance on the practice and guidance from enterprises. Three distinctive evaluation systems are established to make sure the assessment is reasonable. Students' performance is evaluated by the practice unit, teachers and students. A three level evaluation index system is made: level 1 indicator makes it clear that the evaluation object is the assessment on student's practice performance; level 2 indicator is evaluation content, which includes evaluation of the practice enterprises and of the teachers, and system evaluation; level 3 indicator is the main observing point. The corresponding three - level evaluation index system and model is also seen in the teacher's guidance on the practice and guidance from enterprises so as to make a further analysis.

The implementation of AHP algorithm in the evaluation system of post practice of Higher Vocational Colleges is to determine the weights of each evaluation index system. The choice of the weight is actually a process of sorting the assessment index. The implementation process of performance evaluation index weights of student internships are as follows:

(1) The construction of the judgment matrix. According to the established evaluation model on students' practice performance, a pairwise judgment matrix is established in each level, the relevant experts are then required to value each element in the matrix according to the 1-9 scale principle. The constructed judgment matrix is shown in Table 3:

Table 3 The judgment matrix of performance evaluation on student's post practice

\begin{tabular}{|l|l|l|l|}
\hline $\mathrm{A}_{1}$ & $\mathrm{~B}_{1}$ & $\mathrm{~B}_{2}$ & $\mathrm{~B}_{3}$ \\
\hline $\mathrm{B}_{1}$ & 1 & 2 & 5 \\
\hline $\mathrm{B}_{2}$ & $1 / 2$ & 1 & 3 \\
\hline $\mathrm{B}_{3}$ & $1 / 5$ & $1 / 3$ & 1 \\
\hline
\end{tabular}

And then, through the hierarchical single ranking and its consistency check, utilizing formula $C I=\frac{\lambda_{\max }-n}{n-1}$, calculation leads to $\lambda_{\max }=3.0037$, according to which, it is known that $\mathrm{CI}=0.00185$, when $n=3$, $\mathrm{RI}=0.58$, the consistency ratio through calculation is $\mathrm{CR}=0.00319<0.1$, all of which suggest that the constructed judgment matrix conforms to the consistency principle. At this point, the maximum characteristic root of the matrix D corresponds to the standardized feature vector:

$$
W=\left[\begin{array}{l}
0.5816 \\
0.3090 \\
0.1095
\end{array}\right]
$$


In the same way, it can be concluded that other assessment of weight value can be evaluated through student' practice score, so is the consistency check. Here is the weight vector of a set of indicators against the upper level of a certain indicator, calculation of total ranking in each level is necessary, carried out from the highest level to the lowest level layer by layer, and consistency check is also needed. The final overall weight table obtained from evaluation index system of Vocational College Students' internship is as follows:

Table 4 The total weight table of the evaluation on students' post practice score

\begin{tabular}{|c|c|c|}
\hline \multirow{18}{*}{$\begin{array}{l}\text { Evaluati } \\
\text { on on } \\
\text { student's } \\
\text { practice } \\
\text { perform } \\
\text { ance }\end{array}$} & Detail in evaluation index & Index weight value \\
\hline & Evaluation of professional fit for practice enterprises & 0.0212 \\
\hline & $\begin{array}{l}\text { Practical effectiveness of the evaluation of practice } \\
\text { enterprises }\end{array}$ & 0.0425 \\
\hline & professional ethics & 0.1636 \\
\hline & Practice attitude & 0.1636 \\
\hline & Performance on discipline & 0.0783 \\
\hline & Attendance & 0.0298 \\
\hline & Performance on professional ability & 0.0294 \\
\hline & Performance on competence & 0.0534 \\
\hline & Others & 0.097 \\
\hline & Degree of fit of evaluation from guide teacher & 0.0283 \\
\hline & Consistency with graduation design & 0.0094 \\
\hline & Weekly performance & 0.2003 \\
\hline & Summary & 0.0460 \\
\hline & Unity of practice and employment & 0.0087 \\
\hline & Number of practice units & 0.0163 \\
\hline & The total weeks & 0.0912 \\
\hline & exchange intensity between teachers and students & 0.0183 \\
\hline
\end{tabular}

The evaluation system of the post practice in Higher Vocational Colleges based AHP can be divided into three modules, including login module, evaluation module and background management module. The system can be realized by developing three-layer architecture application system software based on B/S model through careful design of the whole system flow chart, together with software engineering principle, designing based on WEB, using ASP technology and database software Microsoft SQL Server2000.

\section{Conclusion}

In summary, vocational college students' practice is an important part of the teaching plan of Higher Vocational Education, so the evaluation of the practice is very important. With the development of computer network technology, the informatization of the Higher Vocational College provides a lot of convenience condition to the improvement of the evaluation mechanism of post practice. Skilled use of the analytic hierarchy process (AHP) method can further construct a comprehensive and complete evaluation system and model on vocational colleges post practice, being scientific, in a large extent reflect the teaching target of internship, and provide more valuable feedback information for the school. This is conducive to the monitor and management of students' post practice, and promote practice management to step on to a new level while improving work efficiency.

\section{Acknowledgements}

In this paper, the research results of the research on the research and practice of school enterprise cooperation in Heilongjiang vocational colleges and universities in Heilongjiang Province, "the 
Twelfth Five Year Plan" of province

\section{References}

[1]Hou Jian-jun. Analysis on the evaluation system construction of internship of higher vocational students[J], Mechanical Occupation Education, 2014 .(12):8-10

[2]Saaty T L.A Scaling. Method for priorities in hierarchical structures[J], Journal of Mathematical Psychology, 1977,15(3): 46-51

[3]Xing De-hai \& Dong Xu-yuan.. The network application of AHP method in the teaching quality evaluation system [J], Computer Engineering and Applications, 2006 (21): 207-209 219

[4]Xu Tong-de \& Zhang Shun-biao. The design and implementation based on analytic hierarchy process (AHP) of teachers in higher vocational colleges teaching quality evaluation system [J], AnHui Electronic Information Vocational and Yechnical College Journal, 2013,12 (6), 28-31

[5]Ni Zhao-rong, Liu Zheng-huai, Zheng Yue-gang \& Jin Jing-jing..The management research and practice of internship in higher vocational students [J], Journal of Jinhua Polytechnic Vocational College Students, 2015,15(3): 19-24

[6]Zheng Wei. The design and implementation of monitoring and management platform of internship in higher vocational college. [D] the Ocean University of China, 2012: 2

[7]Zheng Wei, Tang Rui-chun, The design and implementation of monitoring and management platform of internship in higher vocational college[J]. Computer Programming Skills and Maintenance, 2012(6): 132-133

[8]Pu Hai. The Study on current situation and countermeasures higher vocational students -- Taking Chongqing Industry and Trade Polytechnic as example [D]. Southwest University,2008: 14

[9]Wang Chen. Extended AHP and the application of fuzzy analysis technique in the experimental teaching evaluation [J]. Xi'an University Of Architecture and Technology, 2012: 11

[10]Fang Ke-ya. The desing and implementation based on AHP of internship in higher vocational college [D]Zhejiang University of Technology, 2011: 32-43

[11]Zhao Huan-chen. Analytic hierarchy process,-a simple new decision method[M]Beijing, Science Press, 1986: 1-4

[12]Wang Lin \& Wang Ying-chun. The application of analytic hierarchy process in the assignment of index weights [J].Mathematics research, 2002, 25(24): 303-306 